In man, uric acid is reabsorbed by the tubules; the reabsorption is depressed by 'Diodrast'. It is thus clear that the depression by hippuric acid (or 'Diodrast') cannot be regarded as demonstrating excretion by a common mechanism. Though there is no doubt about the existence of both specific and non-specific competition, it seems that we are at present unable to distinguish between these two phenomena.

Royal College of Agriculture,

I. SPERBER Uppsala 7.

Oet. 14.

'Pitts, Ann. Rev. Physiol., 8, 199 (1946).

Bonsnes, Dill and Dana, J. Clin. Invest., 23, 776 (1944).

\section{Improved Method of Getting Rats' Eggs from the Fallopian Tubes}

RowLANDS ${ }^{1}$ described the recovery of rats' eggs by unravelling the Fallopian tubes and squeezing out their contents under low-power magnification. Using this method he obtained an average of $4 \cdot 9 \pm 0 \cdot 5$ (standard error of the mean) ova per rat from the tubes of thirteen normal rats two days after mating ${ }^{2}$. Using the same method in forty rats killed 0-2 days after mating, we recovered a similar number of eggs $(4 \cdot 2 \pm 0 \cdot 3$ per rat $)$.

A significantly higher average recovery was obtained when the ova were washed out of the Fallopian tubes. A blunted hypodermic needle (26 wire gauge) can easily be inserted into the open ovarian end of the unravelled tube (or into an oblique slit made just below it) and the ova washed out with five to ten drops of physiological saline from a 1-ml. syringe. The washing method is only preferable when the eggs are no longer clumped together surrounded by cumulus cells but are scattered free throughout the length of the tube - that is, more than $24 \mathrm{hr}$. after mating. Before this time the original method is the better one. By the modified technique the average number of eggs recovered from thirty-six rats 0-2 days after mating was $7 \cdot 8 \pm 0 \cdot 4$ eggs per rat, a number more in keeping with the normal litter size.

This work was initiated when one of us (P. C. W.) was Prophit Research Student of the Royal College of Surgeons, and it was aided by an apparatus grant from the University of London.

Courtauld Institute of Biochemistry,

S. A. Simpson

Middlesex Hospital Medical School, London, W.1.

Imperial Cancer Research Fund, P. C. WrmLiams Burtonhole Lane,

Mill Hill, London, N.W.7. ct. 30 .

${ }^{1}$ Rowlands, I. W., Nature, 150, 267 (1942).

Rowlands, I. W., and Williams, P. C., J. Endocrinol., 4, 417 (1946),

\section{Oxidation of Anthracene by Osmium Tetroxide}

WE have shown recently ${ }^{1}$ that the addition of osmium tetroxide to the $9: 10$-positions of phen. anthrene, first observed by Criegee, Marchand and Wannowius ${ }^{2}$, is a general property in a series of tetra- and penta-cyclic aromatic hydrocarbons containing a phenanthrene system. If the reaction is carried out in the presence of pyridine a well-crystal-

lized, deep-coloured, pyridine-osmic ester complex is formed, and this on hydrolysis gives a dihydroxydihydro derivative of the original hydrocarbon.

The presence of a phenanthrene system is not essential, for anthracene and naphthalene form similar coloured complexes. If, in the case of anthracene, the reaction could be limited to addition of osmium tetroxide to one aromatic double bond, then it is probable that hydrolysis would give dl-cis-1 : 2-dihydroanthracene-1 : 2-diol (I), which Boyland and Shoppee ${ }^{3}$ have shown to be the metabolic oxidation product of anthracene in rabbits. Whether the reaction could, in fact, be so limited seemed very doubtful as addition of osmium tetroxide to anthracene takes place slowly, and the product of addition of one molecule of the tetroxide would contain a true ethylenic linkage which should react rapidly with a second molecule of osmium tetroxide with formation of an osmic ester complex of a tetrol.

This conclusion has been verified experimentally, for hydrolysis of the anthracene-osmium tetroxidepyridine complex gave a tetrahydroxytetrahydroanthracene. If the above reasoning is sound, this should be the $1: 2: 3: 4$-tetrahydro compound. That this is indeed the case was supported by a measurement of the ultra-violet absorption spectrum by Mr. E. J. Y. Scott, who found $\log \varepsilon=5 \cdot 25$ at $2330 \mathrm{~A}$. for a methanolic solution of the tetrol $(2 \cdot 34 \mathrm{mgm}$. in $500 \mathrm{ml}$.). This suggests a naphthalene derivative (II), and final confirmation of this was provided by oxidation of the tetrol by alkaline potassium ferricyanide solution to naphthalene-2: 3 dicarboxylic acid, m.p. $238-239^{\circ}$ alone or mixed with a sample prepared by similar oxidation of $2: 3$-dimethylnaphthalene. It is noteworthy that the very reactive meso positions of anthracene are not attacked in this method of oxidation.

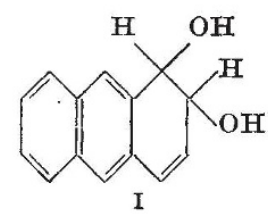

To obtain the tetrol a solution of anthracene $(0.0025$ mol. $)$, osmium tetroxide $(0.005 \mathrm{~mol}$.$) and$ pyridine $(0.01 \mathrm{~mol}$.) in pure benzene $(20 \mathrm{ml}$.) was kept at room temperature for a fortnight with occasional shaking. The brown osmic ester complex which had separated was collected, washed with benzene, and dried in the air. It ( $1 \mathrm{gm}$.) was hydrolysed by heating on the water bath for threequarters of an hour with a solution of crystalline sodium sulphite $(5 \mathrm{gm}$.) in water $(25 \mathrm{ml}$.) and ethanol $(25 \mathrm{ml}$.). More ethanol was then added to precipitate the salts remaining in solution, and the whole was filtered. The black residue was extracted several times with hot alcohol, the extracts combined with the original filtrate, and the combined liquors concentrated under reduced pressure. The solid which separated after cooling was recrystallized from water, giving almost colourless leaflets $(80 \mathrm{mgm}$.$) of$ $1: 2: 3: 4$-tetrahydroxy-1:2:3:4 -tetrahydroanthracene (II), m.p. $241^{\circ}$ (decomp.) (found : C, 68.2; H, 5.8. $\mathrm{C}_{14} \mathrm{H}_{14} \mathrm{O}_{4}$ requires $\mathrm{C}, 68 \cdot 3 ; \mathrm{H}, 5 \cdot 7$ per cent). Its tetraacetate, obtained with boiling acetic anhydridepyridine and purified by chromatography on silica, crystallized from benzene - light petroleum in colour- 